\title{
Editorial 62
}

\author{
Eric Scerri ${ }^{1}$
}

Published online: 26 June 2019

(c) Springer Nature B.V. 2019

In this current International Year for the Periodic Table, the present issue opens, appropriately enough, with an article by Brad Wray on Mendeleev's predictions. In it he argues against a recent claim by Philip Stewart concerning the weighting of Mendeleev's predictions rather than considering all of them as having equal weights. As Wray sees the matter, if Stewart's approach is applied consistently then it risks diminishing the value of some of Mendeleev's famous three predictions concerning gallium, scandium and germanium.

The next brief contribution consists of a response from Philip Stewart, in which he defends his original position concerning the weighting of predictions by claiming that "Getting it right is not equivalent to getting it wrong".

Geoffrey Blumenthal provides the first study of Priestley's late work in chemistry from 1788 onwards, including his late phlogistic theory. This enables the author to give a more nuanced account of Priestley's objections to the new chemistry. As Blumenthal shows, later commentators have taken these objections literally, by not distinguishing between the differing qualities of Priestley's early and late work in chemistry.

Switching to philosophical aspects of chemical education, another frequent contributor to the journal, Peter Nelson, takes on the very general question of "What is chemistry that I may teach it?". This is a deep and thoughtful work that will hopefully be read by chemical educators at large, who regrettably seem to have largely abandoned discussing chemical content only to withdraw into supposedly evidence-based studies of teaching methods, the use of Internet applications, diagnostic testing and all manner of ancillary issues.

The following article comes from China and consists of a network analysis by Liu, Mao and Zhang in which the authors study the degree of similarity between elements in order to probe their chemical reactivity and how many compounds they can form. This is followed by another article in the same general area of network theory, this one from the Colombian author Rosana Suárez. One of her main findings is that classes and blocks of elements show the following increasing order of reactivity, namely nonmetals $>$ semimetals $>$ metals and $\mathrm{p}>\mathrm{s}>\mathrm{d}>\mathrm{f}$.

The issue closes with Juan Quilez from Spain who has conducted a wide-ranging examination of the historical and philosophical aspects of equilibrium theory.

Eric Scerri

scerri@chem.ucla.edu

1 Department of Chemistry and Biochemistry, UCLA, Los Angeles, CA 90095, USA 
Publisher's Note Springer Nature remains neutral with regard to jurisdictional claims in published maps and institutional affiliations. 